\title{
Optimal tuning of proportional-integral controller using system identification for two-phase boost converter for low-voltage applications
}

\author{
M. A. N. Amran', A. A. Bakar ${ }^{2}$, M. H. A. Jalil ${ }^{3}$, A. F. H. A. Gani ${ }^{4}$, and E. Pathan ${ }^{5}$ \\ ${ }^{1-4}$ Faculty of Electrical and Electronic Engineering, University Tun Hussein Onn Malaysia, Malaysia \\ ${ }^{5}$ Department of Electronic Engineering, Quaid-E-Awam University of Engineering, Science \& Technology Nawabshah, \\ Sindh, Pakistan
}

\section{Article Info}

Article history:

Received Jun 25, 2021

Revised Sep 12, 2021

Accepted Sep 20, 2021

\section{Keywords:}

DC-DC converter

System identification

Two-level boost converter

\begin{abstract}
This paper presents modeling and hardware implementations of a two-phase DC-DC boost converter by using the system identification approach. The main objective of this research was to study new methods to obtain the values of the constants for the proportional-integral (PI) controller. Existing methods are time-consuming, since the values of the constants for the PI controller need to be calculated. The system identification approach for the closed-loop boost converter saves more time. To model a two-phase boost converter using the system identification approach, input duty cycle and output voltage are collected in the time domain data. In this study, the transfer function (TF) model, the autoregressive moving average with exogenous (ARMAX) model and the output-error $(\mathrm{OE})$ model were used to generate a mathematical model. To perform the closed-loop analysis, constants $\mathrm{Kp}$ and $\mathrm{Ki}$ were obtained based on the generated mathematical model from the system identification approach. The result from the experiment shows that the percentages of overshoot for the TF, ARMAX and OE models were $19 \%, 25.36 \%$ and $24.6 \%$, respectively. The output voltage ripples obtained for all three models were less than $5 \%$ of output voltage
\end{abstract}

This is an open access article under the CC BY-SA license.

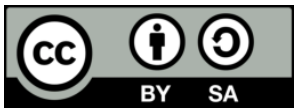

\section{Corresponding Author:}

\section{A. A. Bakar}

Department of Electrical Engineering

Faculty of Electrical and Electronic Engineering, University Tun Hussein Onn Malaysia

Parit Raja, Batu Pahat, Johor, Malaysia

Email: afarul@uthm.edu.my

\section{INTRODUCTION}

Boost converters are used in many applications, such as personal electronic equipment [1], [2], automobiles [3], [4], communications [5], [6] and enterprise systems, also known as enterprise planning systems (ERPs). Boost converters are also widely applied in PV cells [7]-[10] and wind power systems [11][13]. However, conventional boost converters have shortcomings, such as high current ripples on the switch and output diode, difficulty of distinguishing between switching voltage stress and output voltage, and inevitable high losses during switching [14], [15]. Multiple studies in power electronics have successfully demonstrated effective methods to improve boost converters' performance with high efficiency for better output, such as using multiphase DC-DC boost converters or interleaving methods [16]-[19].

Multiphase technology with the interleaved boost converter topology has attracted the attention of many researchers in recent years. This method implements phase-shifted pulse-width modulation (PWM) signals to control the metal-oxide-semiconductor field-effect transistors (MOSFETs) and is often used in 
designs that require parallel components [17]. This article focused on the two-phase DC-DC boost converter, in which the PWM signals of the two-phase boost converter are assigned as a 180-degree phase shift at each level to turn on and off the MOSFETs. An $N$-level boost converter presents a unique characteristic compared with the traditional boost converter topology for its ability to reduce input current ripple, output current ripple and switching stress and to increase load transients [20]-[23].

Adequate information is needed during the process of developing boost converters in order to ensure reliability, effectiveness and robustness of the system. In this study, to obtain the analysis results of the values of constant gains $K_{p}, K_{i}$ and $K_{d}$ in real time, the design simulation of the controller was done, as it was impractical to obtain the constants through physical testing. The most popular methods for adjusting the proportional-integral-derivative controller are the Ziegler-Nichols and the Cohen-Coon tuning methods [24]. However, these methods provide less information about the internal system. The insufficient detailed description of the open-loop system of the two-phase boost converter will lead to an inaccurate design of the controller. In addition, designing hardware in simulation can be time-consuming. To address these issues, the mathematical modeling technique, which comprised the integrated process of formulating sets of equations, was utilized to describe and design the suitable controller for the two-phase boost converter in low-voltage applications.

Basically, there are two ways to design the mathematical model: using the first-principle model via physical laws [25] and using the empirical model via system identification [26]. System identification is a powerful tool for constructing mathematical models based on input and output data. The signal can be measured in the time or frequency domain, depending on the measured data. In general, there are a few steps that must be followed to implement the system identification technique. First, input and output data are collected from the hardware or simulation. Next, a model structure is chosen. The next step is model estimation, in which the most suitable model order for actual measurement is selected, and finally the model is evaluated [27].

This article focused on the transfer function (TF) model, the autoregressive moving average of exogenous (ARMAX) model and the output-error (OE) model to design a mathematical model. Then, the generated mathematical model from the system identification approach was used to design the controller. The values of constants $K_{p}$ and $K_{i}$ of the proportional-integral (PI) controller can be tuned by using the autotuning method. This method used less time when building the controller, as the values of constants $K_{p}$ and $K_{i}$ were tuned according to the mathematical model generated by the system identification method. After successfully obtaining the values of constants $K_{p}$ and $K_{i}$, the values were tested in the developed hardware.

\section{OPERATION OF TWO-PHASE BOOST CONVERTER}

The circuit configuration of the proposed two-phase boost converter is shown in Figure 1. The circuit consisted of two diodes, two switches, two inductors, one capacitor and one resistor. The diodes, switches and inductors were connected in parallel. The operating modes of two-phase boost converter is shown in Table 1.

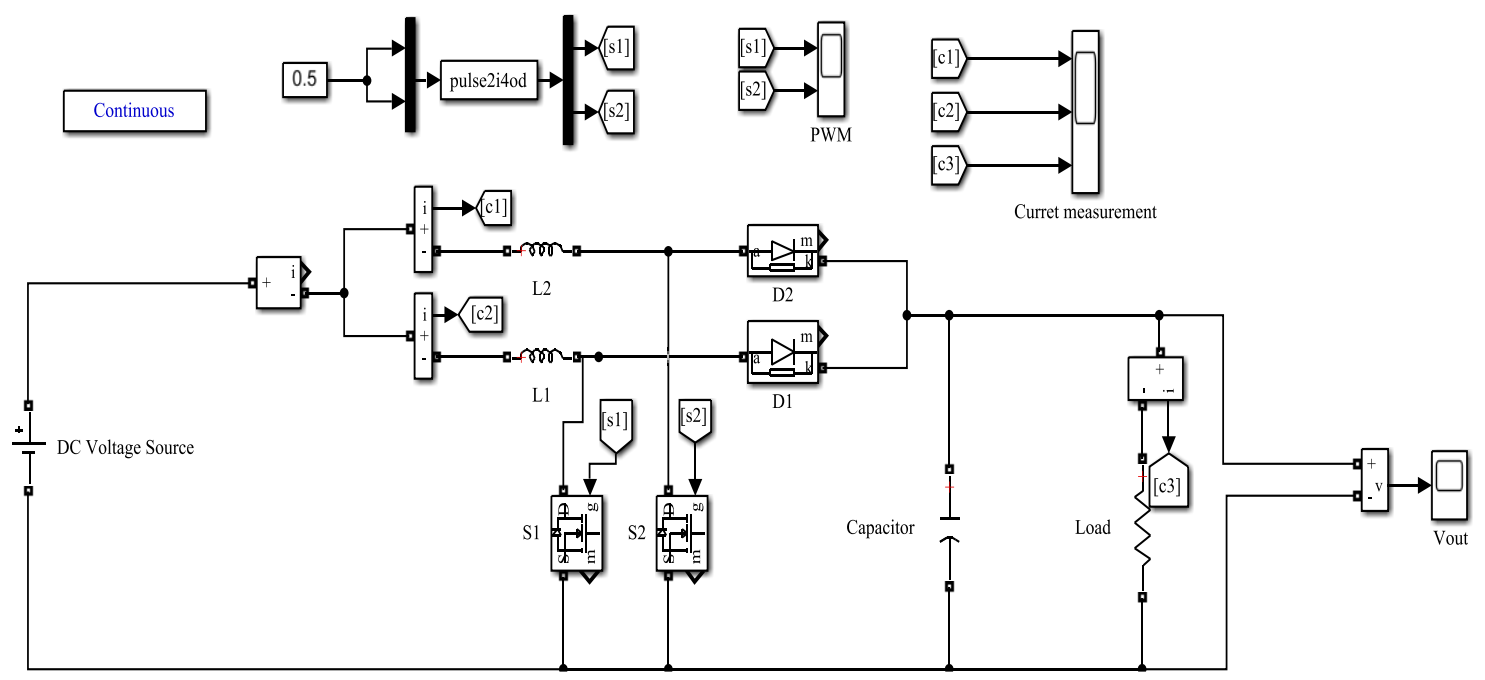

Figure 1. Circuit configuration of two-phase boost converter simulated using MATLAB/Simulink 
Table 1. Operating modes of two-phase boost converter

\begin{tabular}{ccc}
\hline Time & Mosfets, $S$ & Diodes, $D$ \\
\hline$t_{0}-t_{1}$ & $S_{1}$ closed, $S_{2}$ opened & Diode $D_{1}$ in reverse bias, while $D_{2}$ in forward bias \\
$t_{1}-t_{2}$ & $S_{1}$ opened, $S_{2}$ closed & Diode $D_{2}$ in reverse bias, while $D_{1}$ in forward bias \\
\hline
\end{tabular}

- Proportional-integral-derivative algorithm

A proportional-integral-derivative (PID) controller consists of three main components, namely, P, I and D components. A PID controller basically calculates the system's error continuously based on the setpoint value and adjusts the system to provide improvements based on these three components. The P component represents the ratio of the current value of the set value to the process variable error. Component I represent the past error value of the set value of the process variable and integrates it over time to construct the new value of I. Finally, the D component provides the trend to be used to estimate the future error of the set value of the process variable. Even though the PID controller consists of these three main components, each individual component does not necessarily need to be implemented when designing a controller. P, I, D, PI, PD or ID components can also be used, depending on the desired output feedback. The block diagram of a PID controller is shown in Figure 2.

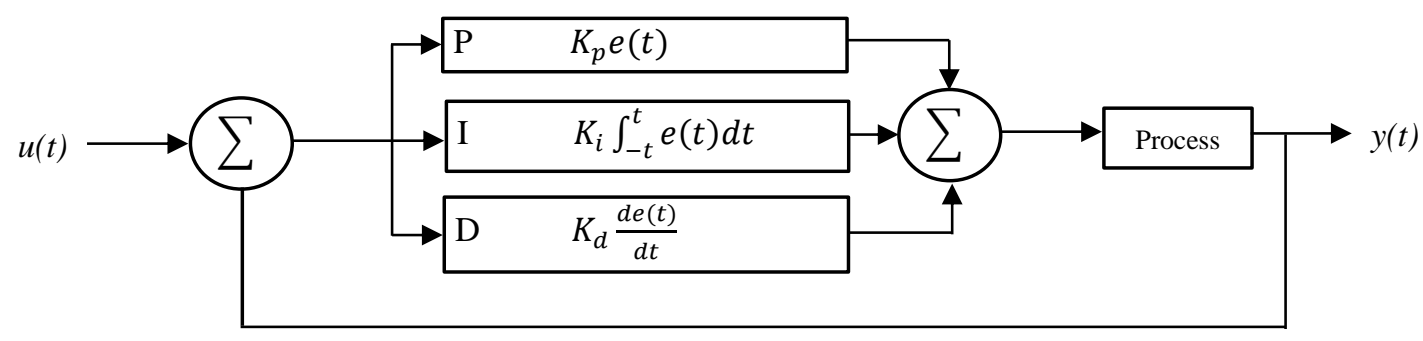

Figure 2. Proportional-integral-derivative controller's block diagram

The PID components will determine the error between the desired set value or reference value and the process variable. Although it can be said that the PID controller is the most traditionally used controller, researchers are still studying to improve its performance and the controls' effects. Two well-known PID tuning methods are the Ziegler-Nichols tuning method and the Cohen-Coon tuning method. Table 2 shows the adjustment rules of the Ziegler-Nichols technology and the Cohen-Coon technology. The value of constant $K$ represents the process gain, $t$ represents time constant, and $\theta$ represents time delay.

Table 2. PID tuning formulas; (a) Ziegler-Nichols and (b) Cohen-Coon

\begin{tabular}{cccc}
\hline Controller & $K_{p}$ & $T_{i}$ & $T_{d}$ \\
\hline $\mathrm{P}$ & $\frac{t}{K \theta}$ & - & - \\
& & & \\
$\mathrm{PI}$ & $\frac{0.9 t}{K \theta}$ & $\frac{\theta}{0.3}$ & - \\
& $\mathrm{O}$ & \\
$\mathrm{PID}$ & $\frac{1.2 t}{K \theta}$ & $2 \theta$ & $2 \theta$ \\
& & & \\
\hline
\end{tabular}

(a)

\begin{tabular}{cccc}
\hline Controller & $K_{p}$ & $T_{i}$ & $T_{d}$ \\
\hline $\mathrm{P}$ & $\frac{t}{K \theta}\left(1+\frac{\theta}{3 t}\right)$ & - & - \\
$\mathrm{PI}$ & $\frac{0.9 t}{K \theta}\left(0.9+\frac{\theta}{12 t}\right)$ & $\theta\left(\frac{30+3\left(\frac{\theta}{t}\right)}{9+20\left(\frac{\theta}{t}\right)}\right)$ & - \\
PID & $\frac{t}{K \theta}\left(\frac{4}{3}+\frac{\theta}{4 t}\right)$ & $\theta\left(\frac{32+\frac{\theta}{t}}{13+8 \frac{\theta}{t}}\right)$ & $\theta\left(\frac{4}{11+2 \frac{\theta}{t}}\right)$ \\
\hline
\end{tabular}

(b) 
Due to advancements in control design, the PID controller can now be adjusted using auto-tuning methods, where the controller is converted into a mathematical model [28]. In the non-linear adjustment process, the Ziegler-Nichols tuning cannot be adjusted due to excessive amplitude modulation and poor load adjustment rate and cannot provide an acceptable response to changes in the setpoint. However, this problem can be addressed by using the automatic adjustment method.

\section{ANALYSIS OF TWO-PHASE BOOST CONVERTER}

A few steps needed to be followed in order to analyze the closed-loop two-phase boost converter. To summarize the steps to perform this setup configuration, Figure 3 and Table 3 show the block diagram of the experiment and the parameters used in the experiment, respectively. Input voltage of $15 \mathrm{~V}$ to $40 \mathrm{~V}$ was supplied to the two-phase boost converter. The load used in this experiment was the programmable AC-DC electronic load from Chroma model 63804. A voltage divider was used to decrease the output voltage of the two-phase boost converter. This was due to the permissible voltage read in the digital signal processing and control engineering (dSPACE) software of only 0-15 V. After that, dSPACE would send the information on the measured voltage to the computer's MATLAB/RTI software. The workflow in MATLAB/Simulink will be explained in the next subsection. After being processed by MATLAB/Simulink, the data were sent to the Quartus II software to generate the switching signals for the closed-loop system. A field-programmable gate array (FPGA) would receive the switching signals, which then were used to operate the gate driver. Finally, the gate driver would drive the MOSFETs to perform the turn-on and turn-off operations.

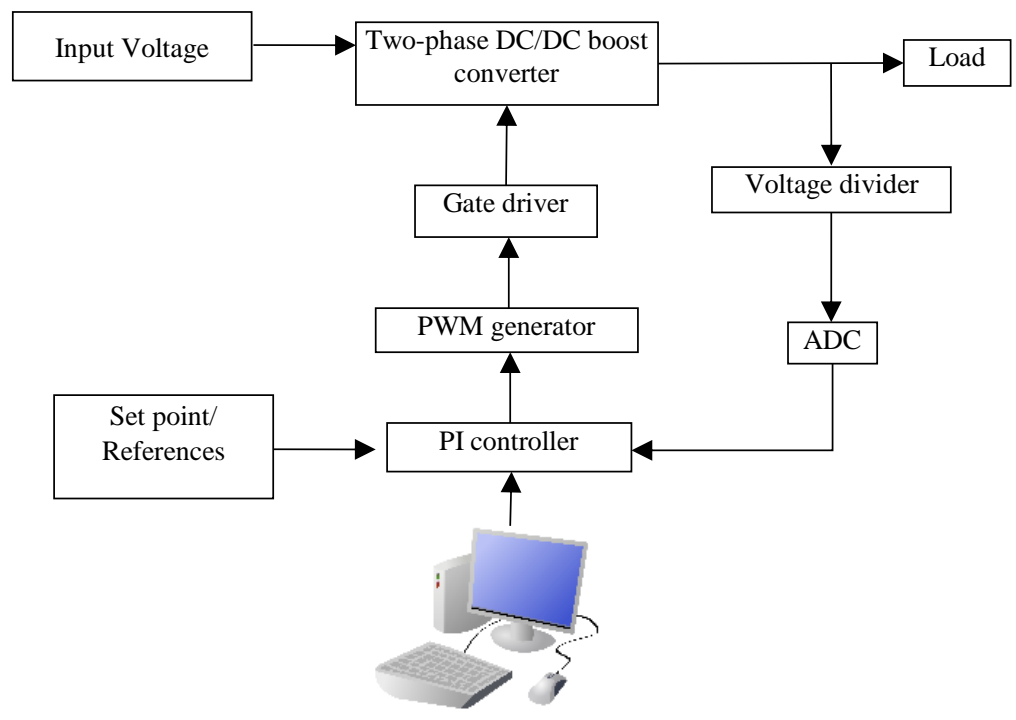

Figure 3. Block diagram of experiment

Table 3. Parameters used in experiment

\begin{tabular}{cc}
\hline Parameter & Value \\
\hline Input voltage & $15-40 \mathrm{~V}$ \\
Output voltage & $45-60 \mathrm{~V}$ \\
Output power & $50-200 \mathrm{~W}$ \\
Switching frequency & $100 \mathrm{kHz}$ \\
Capacitor & $470 \mu \mathrm{F}$ \\
Inductor & $220 \mu \mathrm{F}$ \\
\hline
\end{tabular}

\subsection{MATLAB/Simulink closed-loop design for two-phase boost converter}

The closed-loop design of the two-phase boost converter was programmed by using the MATLAB/Simulink software. Data collection of the measured voltage from dSPACE was obtained from the console, which was linked to MATLAB/Simulink. Figure 4 illustrates the closed-loop program for the twophase boost converter. 


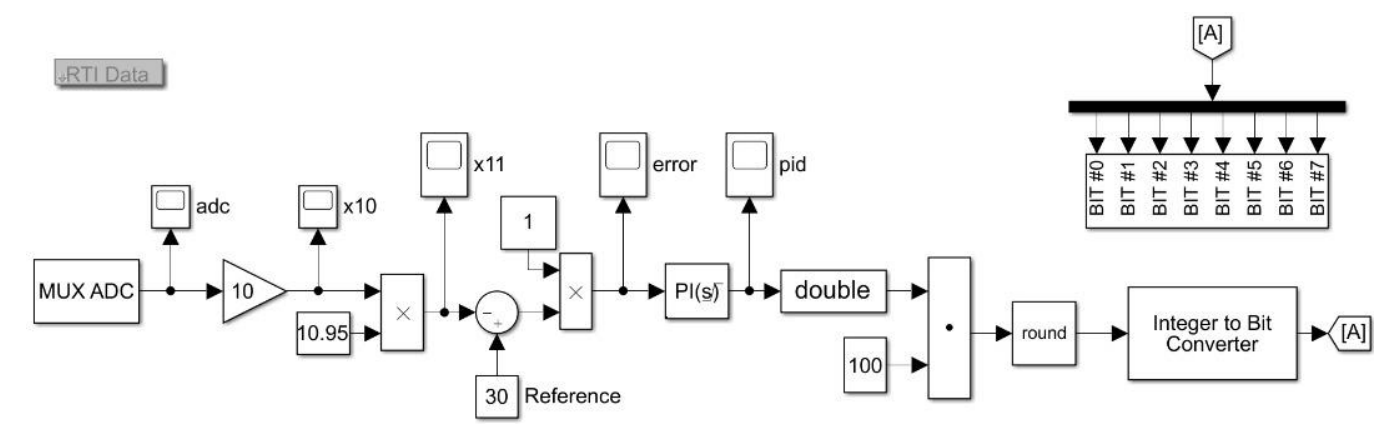

Figure 4. MATLAB/Simulink's closed-loop program for two-phase boost converter by using dSPACE DS1103

The value of the voltage was measured, while the console monitored the dSPACE data during the process of sending the data to the multiplexer (MUX ADC). To increase the input's value, the input data were set to a gain of 10. To make sure that the input measurement factor was the same as the experiment's voltage, the input test voltage was multiplied by 10.95 . The input value was compared with the setpoint value so that the PI controller followed the setpoint. The output of the PI controller was set to double and multiplied by a constant using the rounding function block. Next, the input was converted from integer to bit. After converting, 8 bits of the 32-bit digital output were synchronized using the Quartus II software for the Altera DE2-70 board.

\subsection{Quartus II design for interleaved switching signal}

In order to drive the MOSFETs, the gate voltage needed to be increased. Accordingly, the MOSFETs must be connected to the gate driver. Therefore, an adequate level of voltage was required to drive the MOSFETs. Quartus II is one of the software that could be used for this purpose. Figure 5 shows the block diagram to generate the switching signals for the two-phase boost converter.

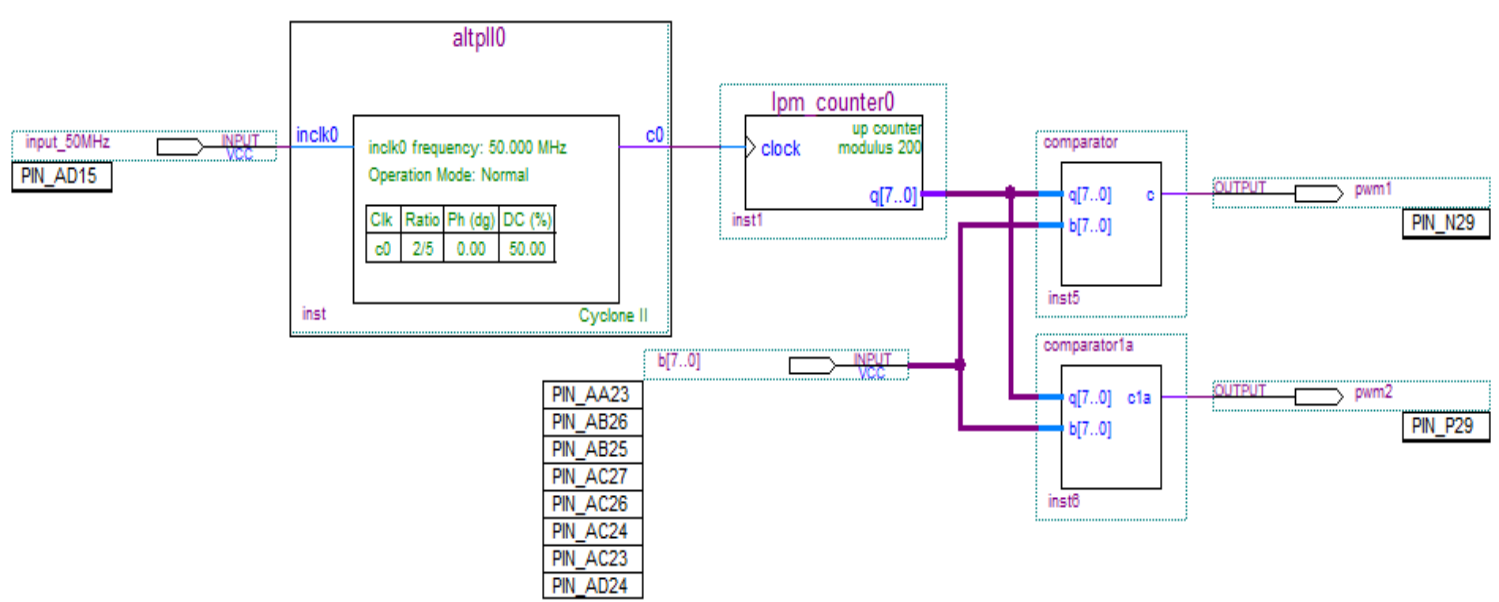

Figure 5. Quartus II software's block diagram to generate switching signals

The interleaved switch design for driving the MOSFETs included altpll, lpm_counter and two comparators. The altpll function, or the phase-locked loop, was capable of adjusting the phase of the locally generated signal to match the phase of the input signal. In addition, the feedback control system of the phaselocked loop can generate a stable frequency for the input. As for the switch, PIN_AD15 was connected to the $50 \mathrm{MHz}$ input of the internal clock. The internal clock would generate $10 \mathrm{MHz}$ output. The lpm_counter function can be used to create up/down counters, up counters and down counters. A maximum counter of approximately 256 bits can be generated by lpm_counter. For the proposed two-phase boost converter, an 8bit lpm_counter was implemented. Although the input of lpm_counter was set to 7 bits, since the switch input of dSPACE was set to 8 bits, the system needed to be standardized to 8 bits in order to operate. The 
lpm_counter function would count from 0 to 199. As for the comparators, VHDL or Very High Description Language was used to design the interleaved switching.

\section{RESULTS AND DISCUSSION}

To analyze the output voltage from the two-phase boost converter, some equipment needed to be prepared. Figure 6 shows the equipment used to analyze the closed-loop two-phase boost converter designed using the system identification approach. The equipment consisted of Altera DE2-70 from Intel as the signal generator, with a $50 \mathrm{MHz}$ oscillator and a $28.63 \mathrm{MHz}$ oscillator as the clock source. The gate driver was used to drive the MOSFETs into the on-state or off-state. For the two-phase boost converter's voltage supply, model VSP12010 programmable DC voltage supply from B\&K Precision Corporation was selected since it can provide power of up to $1,200 \mathrm{~W}$.

The dSPACE DS1103 controller was used to collect the output voltage, which would interface with the control desk to analyze the output voltage. To make sure current flowed in the components, programmable AC-DC electronic load from Chroma model 63804 was used to set the load. The advantage of the programmable AC-DC electronic load was that it can support power of up to 45,000 W with voltage of up to $350 \mathrm{~V}_{\mathrm{rms}}$ and current of up to $45 \mathrm{~A}_{\mathrm{rms}}$. Figure 6 shows the experiment setup for the two-phase boost converter.

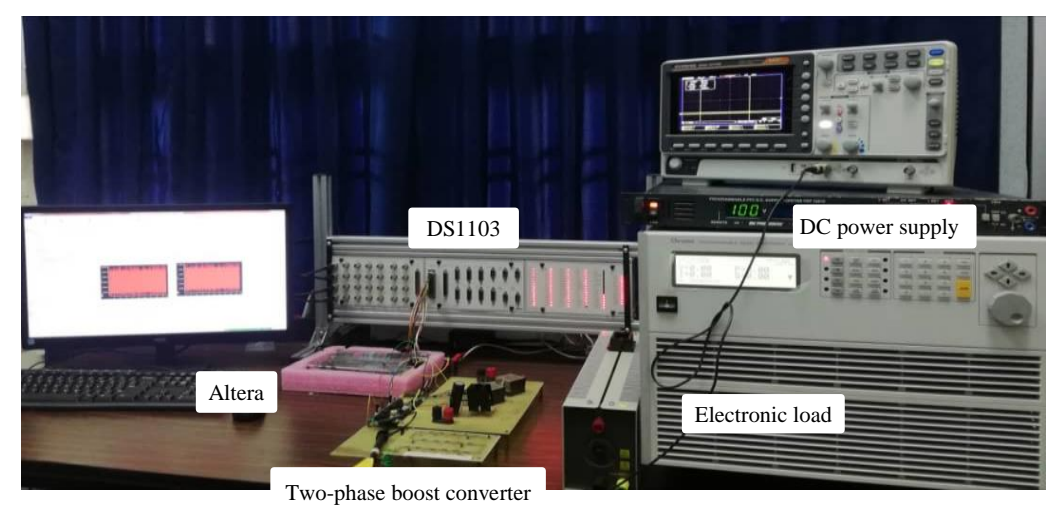

Figure 6. Experiment setup for two-phase boost converter

\subsection{Transient response from the three models}

This section explains the results of the transient response of the two-phase boost converter. From the output response, a sudden change in voltage occurred with a short burst of energy, which caused a transient response. An analysis was performed to see the system's response over a period of time. The analysis was performed from $0 \mathrm{~V}$, and $20 \mathrm{~V}$ was injected with the reference voltage of $25 \mathrm{~V}$. The resistor was set to $20 \Omega$ by using the variable resistor.

The analysis used three different sets of values of $K_{p}$ and $K_{i}$. The first set of values of $K_{p}$ and $K_{i}$ were from the TF model, the second set of values of $K_{p}$ and $K_{i}$ were from the ARMAX model and the third set of values of $K_{p}$ and $K_{i}$ were from the OE model. Table 4 shows the values of constants $K_{p}$ and $K_{i}$ from the autotuning method with the system identification approach.

Table 4. Constants $K_{p}$ and $K_{i}$ for TF, ARMAX and OE models

\begin{tabular}{lcc}
\hline Model & $K_{p}$ & $K_{i}$ \\
\hline TF & 0.000523569507730620 & 4.33909483492499 \\
ARMAX & 0.001587442646336000 & 4.78925750164727 \\
OE & 0.000457947276794796 & 6.31888447044734 \\
\hline
\end{tabular}

From the responses shown in Figure 7, the ARMAX model showed the highest overshoot, which was $25.36 \%$, followed by the OE model with $24.6 \%$ and the TF model with $19 \%$. The delay time for the TF model was the fastest, which was $0.0152928 \mathrm{~s}$, while the ARMAX model and the OE model had the same delay time, which was $0.016192 \mathrm{~s}$. Next, the rise time for the TF model had the fastest response with $0.0135936 \mathrm{~s}$ compared with those of the ARMAX and OE models with $0.0143936 \mathrm{~s}$ each. Finally, for settling 
time, the OE model showed the fastest response with $0.0469979 \mathrm{~s}$ compared with those of the TF and ARMAX models with $0.0539975 \mathrm{~s}$ and $0.0539976 \mathrm{~s}$, respectively. The responses obtained from the transient analysis for the TF, ARMAX and OE models are tabulated in Table 5.

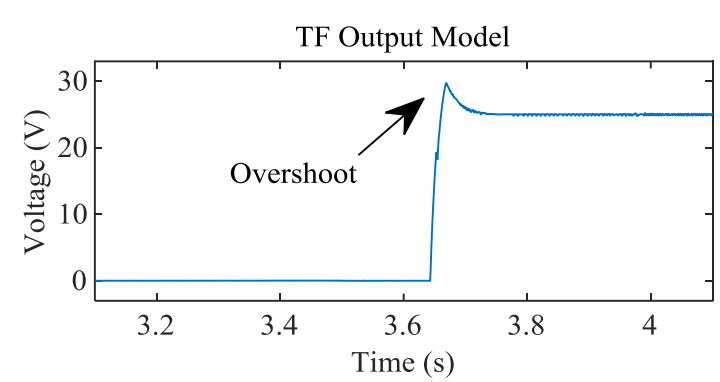

(a)

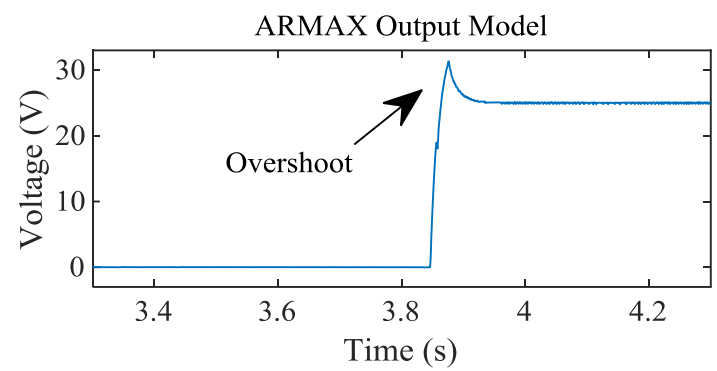

(b)

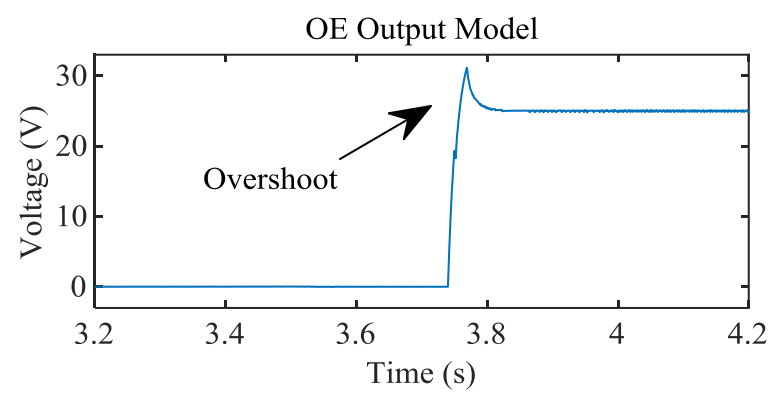

(c)

Figure 7. Transient response for; (a) TF model, (b) ARMAX model and (c) OE model

Table 5. Models' response obtained from transient analysis

\begin{tabular}{ccccc}
\hline Model & Percentage of overshoot $(\%)$ & Delay time $(\mathrm{s})$ & Rise time $(\mathrm{s})$ & Settling time (s) \\
\hline TF & 19.00 & 0.0152928 & 0.0135936 & 0.0529975 \\
ARMAX & 25.36 & 0.0161928 & 0.0143936 & 0.0539976 \\
OE & 24.60 & 0.0161928 & 0.0143936 & 0.0469979 \\
\hline
\end{tabular}

\subsection{Output voltage ripples from system identification approach}

Voltage ripples cannot be avoided in output voltage. Output voltage ripples are often generated even in small magnitudes, depending on certain conditions. If the voltage is high, thousands of ripples may be generated. The output voltage analysis consisted of two conditions. The first condition was for $30 \mathrm{~W}$ power and the second condition was for $150 \mathrm{~W}$ power. The load applied in this experiment was set by Chroma model 63804 programmable AC-DC electronic load. The resistor was fixed at $20 \Omega$ to observe the differences in the various values of $K_{p}$ and $K_{i}$ from the system identification approach.

In order to evaluate the system's voltage ripple, a number of samples were collected. The time used to analyze the percentage of voltage ripple was $2 \mathrm{~s}$ (steady state). From the data samples, the highest voltage and the lowest voltage were recorded and used to calculate the percentage of voltage ripple by using (1).

$$
r=\frac{V_{\max }-V_{\min }}{V_{\text {avg }}} \times 100
$$

Figures 8, 9 and 10 depict the output voltage results for the TF, ARMAX and OE models, respectively. From the results, the TF model for $30 \mathrm{~W}$ showed $2.72 \%$ output voltage ripple, while the TF model for $150 \mathrm{~W}$ showed $2.10 \%$. The ARMAX model showed $4.20 \%$ output voltage ripple for $30 \mathrm{~W}$ and $2.68 \%$ for $150 \mathrm{~W}$. Finally, the OE model showed $3.04 \%$ output voltage ripple for $30 \mathrm{~W}$ and $2.24 \%$ for 150 W. For $30 \mathrm{~W}$, the TF model showed the lowest percentage of output voltage ripple with a difference of $1.48 \%$ from that of the ARMAX model and $0.32 \%$ from that of the OE model. For $150 \mathrm{~W}$, the TF model also showed the lowest percentage of voltage ripple with a difference of $0.58 \%$ from that of the ARMAX model and $0.14 \%$ from that of the OE model. The percentages of output ripple for $30 \mathrm{~W}$ and $150 \mathrm{~W}$ from the system identification approach are tabulated in Table 6. 


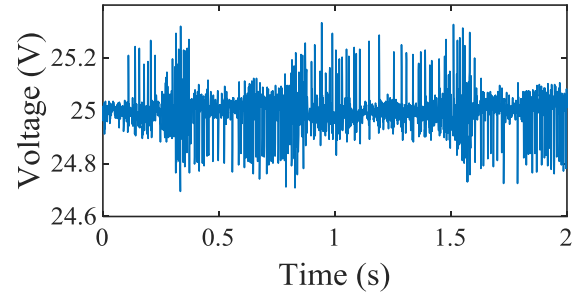

(a)

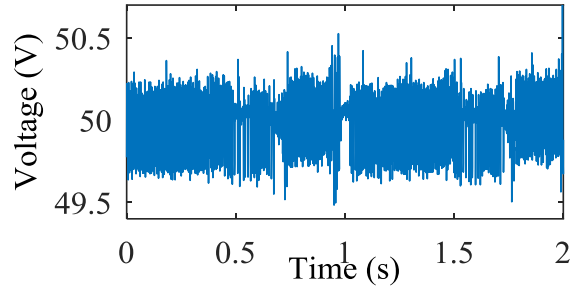

(b)

Figure 8. Output voltage ripples for TF model with $K_{p}=0.00052356950773062$ and $K_{i}=4.33909483492499$; (a) $30 \mathrm{~W}$ and (b) $150 \mathrm{~W}$

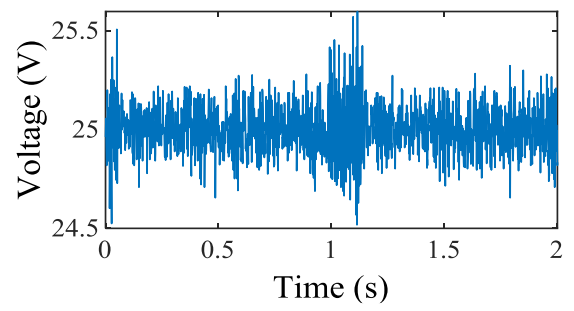

(a)

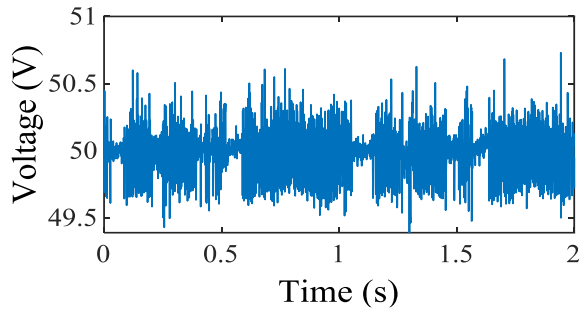

(b)

Figure 9. Output voltage ripples for ARMAX model with $K_{p}=0.001587442646336$ and $K_{i}=4.78925750164727$; (a) $30 \mathrm{~W}$ and (b) $150 \mathrm{~W}$

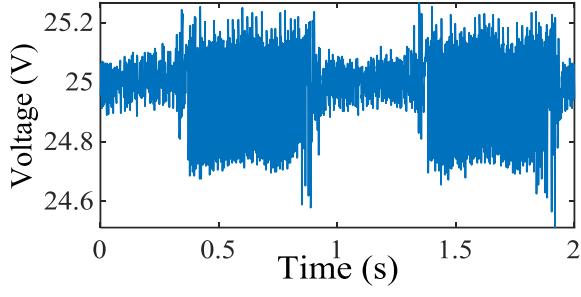

(a)

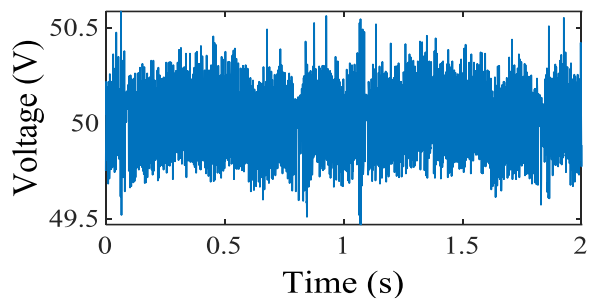

(b)

Figure 10. Output voltage ripples for OE model with $K_{p}=0.000457947276794796$ and $K_{i}=6.31888447044734$; (a) $30 \mathrm{~W}$ and (b) $150 \mathrm{~W}$

Table 6. Percentages of output ripple for $30 \mathrm{~W}$ and $150 \mathrm{~W}$ from system identification approach

\begin{tabular}{ccc}
\hline Model & Types & Percentage of output voltage ripple \\
\hline \multirow{2}{*}{ TF } & $30 \mathrm{~W}$ & $2.72 \%$ \\
& $150 \mathrm{~W}$ & $2.10 \%$ \\
\multirow{2}{*}{ ARMAX } & $30 \mathrm{~W}$ & $4.20 \%$ \\
\multirow{2}{*}{ OE } & $150 \mathrm{~W}$ & $2.68 \%$ \\
& $30 \mathrm{~W}$ & $3.04 \%$ \\
& $150 \mathrm{~W}$ & $2.24 \%$ \\
\hline
\end{tabular}

\section{CONCLUSION}

Optimal tuning of the PI controller by using the system identification approach for the closed-loop two-phase boost converter was proposed to generate an efficient and fast-responding controller. The method implemented in this study was an improvement of the popular tuning methods, which were the ZieglerNichols and the Cohen-Coon tuning methods. In real-life applications, the system identification approach is far less time-consuming when designing a controller for the DC-DC boost converter. This is due to the system identification being able to generate the mathematical model of the boost converter by using input and output data. The input data from this proposed experiment were the PWM signals and the output data were 
the output voltages. The collected data were sent for system identification to generate the mathematical model. After obtaining the mathematical model, it was used to find the values of constants $K_{p}$ and $K_{i}$. Three models were applied from the system identification approach to generate the mathematical model, which were the transfer function (TF), autoregressive moving average with exogenous input (ARMAX), and outputerror (OE) models. The constants for the TF model were observed to be the best, since the model produced lower percentages of overshoot and voltage ripple compared with those of the ARMAX and OE models. Therefore, the contribution of this paper is to provide the fastest method to design the controller for a DC-DC boost converter.

\section{ACKNOWLEDGEMENTS}

The authors would like to express their deepest appreciation to Universiti Tun Hussein Onn Malaysia for supporting this research under TIER 1 Vot H909 research grant.

\section{REFERENCES}

[1] J. W. Kim and P. Jang, "Improved droop method for converter parallel operation in large-screen LCD TV applications," Journal of Power Electronics., vol. 14, no. 1, pp. 22-29, 2014, doi: 10.6113/JPE.2014.14.1.22.

[2] F. M. Shahir, E. Babaei and M. Farsadi, "Extended Topology for a Boost DC-DC Converter," in IEEE Transactions on Power Electronics, vol. 34, no. 3, pp. 2375-2384, March 2019, doi: 10.1109/TPEL.2018.2840683.

[3] F. S. Alargt and A. S. Ashur, "Analysis and simulation of interleaved boost converter for automotive applications," Journal of Engineering and Innovative Technology (IJEIT), vol. 2, no. 11, pp. 76-82, 2013.

[4] A. Isurin and A. Cook, "Step-up DC-DC converter for automotive application," 2016 18th European Conference on Power Electronics and Applications (EPE'16 ECCE Europe), 2016, pp. 1-9, doi: 10.1109/EPE.2016.7695284.

[5] B. M. Hasaneen and A. A. Elbaset Mohammed, "Design and simulation of DC/DC boost converter," 2008 12th International Middle-East Power System Conference, 2008, pp. 335-340, doi: 10.1109/MEPCON.2008.4562340.

[6] A. F. H. A. Gani, A. A. Bakar, A. Ponniran, M. Hussainar, and M. A. N. Amran, "Design and development of PWM switching for 5-level multiphase interleaved DC/DC boost converter," International Journal of Electrical and Computer Engineering, vol. 17, no. 1, pp. 131-140, 2019, doi: 10.11591/ijeecs.v17.i1.pp131-140.

[7] M. Pushpavalli and N. M. Jothi Swaroopan, "Performance analysis of hybrid photovoltaic/wind energy system using KY boost converter," International Journal of Power Electronics and Drive Systems, vol. 10, no. 1, p. 433, 2019, doi: 10.11591/ijpeds.v10.i1.pp433-443.

[8] N. Hashim, Z. Salam, D. Johari, and N. F. N. Ismail, "DC-DC boost converter design for fast and accurate MPPT algorithms in stand-alone photovoltaic system," International Journal of Power Electronics and Drive Systems, vol. 9, no. 3, pp. 1038-1050, 2018, doi: 10.11591/ijpeds.v9n3.pp1038-1050.

[9] A. Ramesh, M. S. Kumar, and O. C. Sekhar, "Interleaved boost converter fed with PV for induction motor/agricultural applications," International Journal of Power Electronics and Drive Systems, vol. 7, no. 3, pp. 835-853, 2016, doi: 10.11591/ijpeds.v7.i3.pp835-853.

[10] J. Divya Navamani, K. Vijayakumar, and J. Jegatheesan, "Study on high step-up DC-DC converter with high gain cell for PV applications," Procedia Computer Science, vol. 115, pp. 731-739, 2017, doi: 10.1016/j.procs.2017.09.109.

[11] R. S. Pukale, A. Gurav, M. A. Rahul Kadam, A. Sutar, and P. Bandgar, "Small scale horizontal wind turbine system using DC-DC boost converter," International Research Journal of Engineering and Technology (IRJET), vol. 3, no. 2, pp. 1649-1653, 2016.

[12] K. K. Desai Rohan V Gavali, S. D. Kanase Sumit S Karande, and N. M. Jamadar, "Application of buck-boost converter for wind energy control," International Journal for Innovative Research in Science \& Technology, vol. 3, no. 10, pp. 156-160, 2017, doi: 10.5281/zenodo.2651002.

[13] L. Stefan and F. Yusivar, "Modeling of Wind Turbine Generator with Boost Converter MPPT," 2018 2nd International Conference on Smart Grid and Smart Cities (ICSGSC), 2018, pp. 100-104, doi: 10.1109/ICSGSC.2018.8541306.

[14] W. Li, X. Lv, Y. Deng, J. Liu and X. He, "A Review of Non-Isolated High Step-Up DC/DC Converters in Renewable Energy Applications," 2009 Twenty-Fourth Annual IEEE Applied Power Electronics Conference and Exposition, 2009, pp. 364-369, doi: 10.1109/APEC.2009.4802683.

[15] A. Thiyagarajan, S. G. Praveen Kumar and A. Nandini, "Analysis and comparison of conventional and interleaved DC/DC boost converter," Second International Conference on Current Trends In Engineering and Technology ICCTET 2014, 2014, pp. 198-205, doi: 10.1109/ICCTET.2014.6966287.

[16] M. A. Devi, K. Valarmathi and R. Mahendran, "Ripple current reduction in interleaved boost converter by using advanced PWM techniques," 2014 IEEE International Conference on Advanced Communications, Control and Computing Technologies, 2014, pp. 115-119, doi: 10.1109/ICACCCT.2014.7019291.

[17] K. Kroics, J. Zakis and U. Sirmelis, "Multiphase interleaved DC-DC converter with directly and inversely coupled inductors," 2016 57th International Scientific Conference on Power and Electrical Engineering of Riga Technical University (RTUCON), 2016, pp. 1-6, doi: 10.1109/RTUCON.2016.7763102.

[18] M. Schuck and R. C. N. Pilawa-Podgurski, "Ripple minimization in asymmetric multiphase interleaved DC-DC switching converters," 2013 IEEE Energy Conversion Congress and Exposition, 2013, pp. 133-139, doi: 
10.1109/ECCE.2013.6646691.

[19] A. A. Bakar, M. U. Wahyu, A. Ponniran, and T. Taufik, "Simulation and analysis of multiphase boost converter with soft-switching for renewable energy application," International Journal of Power Electronics and Drive Systems, vol. 8, no. 4, pp. 1894-1902, 2017, doi: 10.11591/ijpeds.v8i4.pp1894-1902.

[20] A. A. Bakar, W. M. Utomo, A. Ponniran, and T. Taufik, "Simulation and analysis of multiphase boost converter with soft-switching for renewable energy application," International Journal of Power Electronics and Drive Systems, vol. 8, no. 4, pp. 1894-1902, 2017, doi: 10.11591/ijpeds.v8i4.pp1894-1902.

[21] B. Axelrod, Y. Beck, and Y. Berkovich, "High step-up DC-DC converter based on the switched-coupled-inductor boost converter and diode-capacitor multiplier: steady state and dynamics," IET Power Electronics, vol. 8, no. 8, pp. 1420-1428, 2015, doi: 10.1049/iet-pel.2014.0785.

[22] K. H. Jasmine and C. Reshma Raj, "A high gain boost converter with input current ripple reduction," 2014 International Conference on Circuits, Power and Computing Technologies [ICCPCT-2014], 2014, pp. 455-460, doi: 10.1109/ICCPCT.2014.7054918.

[23] A. A. Bakar, W. M. Utomo, T. Taufik, and A. Ponniran, "Modeling of FPGA-and DSP-based pulse width modulation for multi-input interleaved DC/DC converter," International Review of Electrical Engineering, vol. 14, no. 1, pp. 79-85, 2019, doi: 10.15866/iree.v14i1.13928.

[24] A. R. Nikhar, S. M. Apte and R. Somalwar, "Review of various control techniques for DC-DC interleaved boost converters," 2016 International Conference on Global Trends in Signal Processing, Information Computing and Communication (ICGTSPICC), 2016, pp. 432-437, doi: 10.1109/ICGTSPICC.2016.7955340.

[25] A. K. Singh, B. Tyagi and V. Kumar, "First principle modeling and neural network-based empirical modeling with experimental validation of binary distillation column," Chemical Product and Process Modeling, vol. 8, no. 1, pp. 53-70, 2013, doi: 10.1515/cppm-2013-0011.

[26] A. Patil and S. More, "Mathematical modeling of physical system," IOSR Journal of Electrical and Electronics Engineering, vol. 9, no. 3, pp. 57-64, 2014, doi: 10.9790/1676-09325764.

[27] M. A. N. Amran, A. A. Bakar, M. H. A. Jalil, M. U. Wahyu, and A. F. H. A. Gani, "Simulation and modeling of two-level DC/DC boost converter using ARX, ARMAX, and OE model structures," Indonesian Journal of Electrical Engineering and Computer Science, vol. 18, no. 3, pp. 1172-1179, 2020, doi: 10.11591/ijeecs.v18.i3.pp1172-1179.

[28] R. P. Borase, D. K. Maghade, S. Y. Sondkar, and S. N. Pawar, "A review of PID control, tuning methods and applications," in International Journal of Dynamics and Control, 2020, no. July, doi: 10.1007/s40435-020-00665-4. 